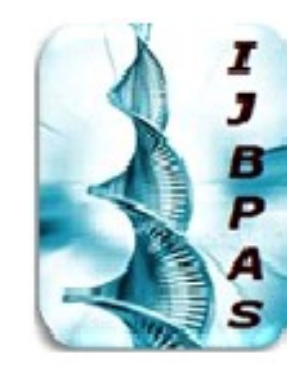

International Journal of Biology, Pharmacy and Allied Sciences (IJBPAS) 'A Bridge Betuen caboratory and QRender'

\author{
WWW.ijbpas.com
}

\title{
PRODUCTION OF ALTERNATE FUEL FROM CHEMICAL INDUSTRY WASTE: \\ A CASE STUDY OF SIPCOT INDUSTRIAL AREA
}

\section{T. POONKUNDRAN*}

Dept. of Civil Engineering, Faculty of Engg. \& Tech., Annamalai University, Annamalai Nagar,

Tamil Nadu- 608002

*Corresponding Author E Mail: geepoo76@rediffmail.com

Received 19 ${ }^{\text {th }}$ Aug. 2019; Revised $8^{\text {th }}$ Sept. 2019; Accepted $5^{\text {th }}$ Sept. 2019; Available online $1^{\text {st }}$ Feb. 2020

https://doi.org/10.31032/IJBPAS/2020/9.2.4941

Abstract: Alternate fuel and raw material (AFR) recovery from hazardous industrial waste has gained popularity in recent past. The recovery not only facilitates waste minimization, but also reduces incineration burden. The present study involves the investigation on characteristics, quantity, existing disposal pathway for various wastes generated from SIPCOT, Cuddalore. Investigation reveals that the majority of the waste generated from the industrial estates including wastewater disposed or stored unscientifically, causing health and environmental catastrophe. The local industries majorly generate wastes of corrosive nature and is of no contribution from recovery/recycling perspective. Only three industries identified as Pioneer Miyagi Chemicals, SPIC Pharmaceuticals Division, and Loyal Super Fabrics Limited produce wastes of higher calorific value (CV) such as spent solvents, discarded medicines, and damaged fabrics respectively. The crucial characteristics such as heating value, moisture content, ash content, and chloride $\&$ sulphate content were analysed and observed as 4787,4528 , and $2528 \mathrm{cal} / \mathrm{gm} ; 6.5 \%, 3.8 \%, 5 \% ; 3.4 \%, 6 \%, 12.5 \% ; 0.8 \%, 3.2 \%$, $0.4 \% ; 1.2 \%, 4.7 \%, 0.8 \%$ respectively in above sequence. Damaged fabrics were shredded and mixed with discarded medicines in 1:1 ratio to compensate the excessive chloride and sulphate content, whereas spent solvent was solely well enough to be utilized as AFR. The mixed AFR sample (M1) had a CV of $3476 \mathrm{cal} / \mathrm{gm}$ with chloride and sulphate content of $1.7 \%$ and $2.53 \%$ respectively. Thus the present study suggests to develop an alternate waste disposal pathway for the above industries by collaborating with local cement industries and facilitate revenue recovery.

Keywords: Alternate fuel, Calorific value, industrial waste, SIPCOT, Waste to wealth 


\section{INTRODUCTION}

Industrial waste is hazardous in nature. Wide range of industries produces varieties of waste includes: expired chemicals, toxic substances, sludge, etc. [1]. Majority of these wastes are dry in nature and have moderate to good burning value. Previously, there were three major pathways utilized for the disposal of any industrial waste namely, direct landfill (DLF), landfill after treatment (LAT), and incineration [2]. All the treatments are nonsustainable with space occupancy, and zero recovery. The concept of AFR was first introduced in 2016 in new solid waste management (SWM) rule [3]. Since then there has been a revolution in cement industries. Many production giants such as Bharti cement, Ambuja cement etc. have already started adopting the usage of AFR apart from the regular coal feed [4]. But the production is still not on par with the demand. There are only two industrial waste management (IWM) facilities of Ramkygroup located at Mumbai and Hyderabad producing AFR on regular basis. The production is around 1100 and 800 tons/annum respectively [5]. Whereas, the global requirement of coal in cement industries is about 330 Mt/annum. Therefore in order to meet the requirement there is a need of identification of new potential sources and establishment of IWM facilities for sufficient production [6].
Simultaneously more number of cement industries need to make the arrangement of separate kiln to facilitate the consumption of AFR. It may help to meet the energy demand and save valuable fossil fuel resources.

The main objective of the present study was to analyse the characteristics of the waste generated from SIPCOT and explore the potential of it to develop a suitable disposal pathway. Also, to understand the potential of waste for AFR processing and develop a sustainable business model with the nearby potential consumers.

\section{MATERIALS AND METHOD}

The process involves investigation for waste suitability to be processed as AFR, quantification, explore local clients, and possible opportunities for the SIPCOT industries to minimize waste treatment charges. The onsite physical verification and collection were carried out within SIPCOT, Cuddalore and analytical studies were carried out at Annamalai University. Further details are furnished below.

\section{Industrial Classification}

Before the actual onsite visit, the list of companies procured and industries were separated into three broad categories: chemical manufacturing industries, pharmaceutical industries, and fabric manufacturing industries. Each category further consists of several manufacturing 
units. There are total 2413 industries operating in SIPCOT presently out of which 1644 is from category 1,638 is pharma units, and the remaining 131 is fabric manufacturing industries. The distribution module is further portrayed in Figure 1.

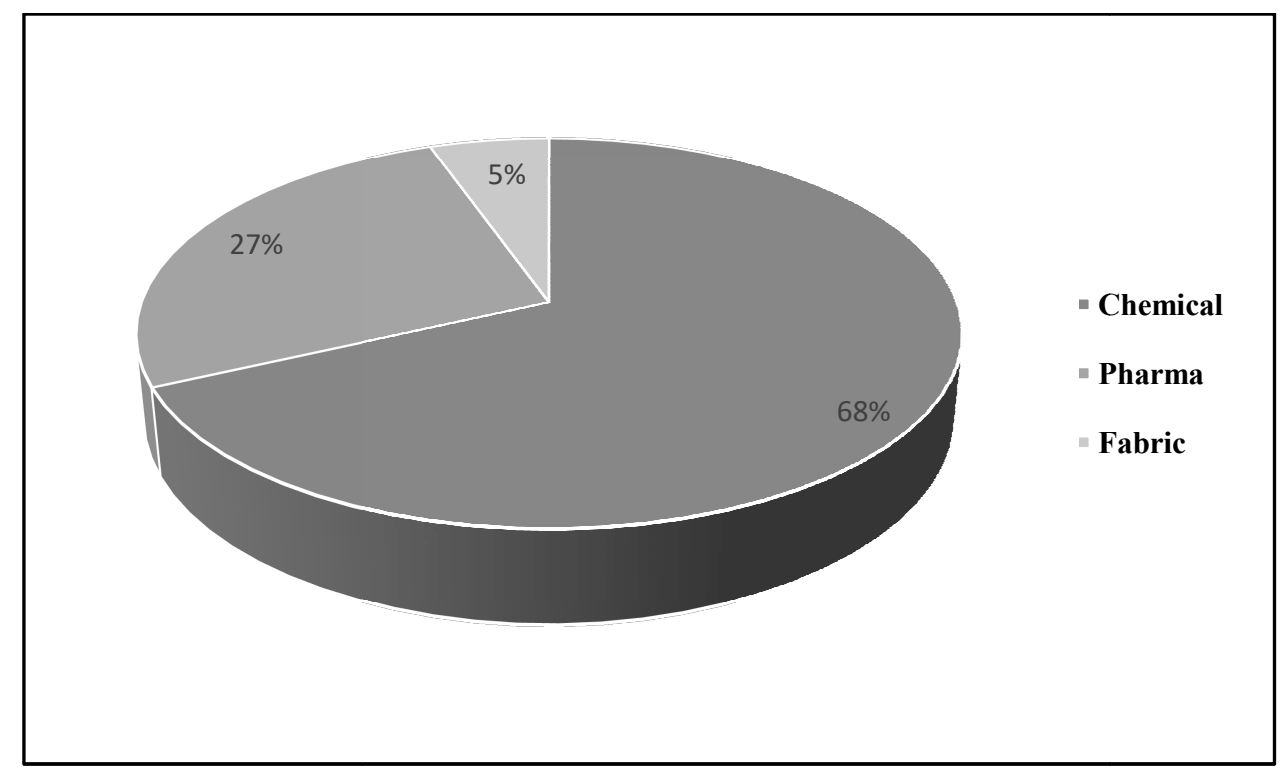

Figure 1: Percentile distribution of industries in SIPCOT, Cuddalore

\section{Waste Identification}

The generated waste is highly heterogeneous in nature and varies on the industry to industry basis. Still, the present study tried to establish a harmony between the wastes from a similar category of industries. Chemical industries generate majorly expired hazardous chemicals, corrosive acids, and bases, but contradictorily, there are few paint industries such as Pioneer Miyagi Chemicals, Asian Paints etc. produce spent solvents which is of major interest. Furthermore, pharmaceutical industries generate organic solvents, discarded drugs, and medicines etc. as waste which is of significant calorific value. The fabric units also have wastes of greater calorific value but is of minor contribution in terms of quantity. The total quantity of waste generated 3.75 lakhs tonnes per annum. On average the waste production rate is $34 \%$, $12.5 \%$, and $7.6 \%$ respectively for chemical, pharma, and fabric industries against the production.

\section{Waste Characterization}

The major criteria of waste to be qualified for AFR includes high $\mathrm{CV}$, low moisture, ash, and salt content. Therefore, an interview was conducted with the company authorities based on the output of the literature study. Shortlisted pharms were contacted and the approval rate of data sharing was $78 \%$ (calculated against the total value of 478 industries). Informations were gathered on-field and specimen were 
collected physically. All the samples went through experiments such as loss on drying (LOD) \& loss on ignition (LOI) analysis, calorific value by semi-automatic bomb calorimeter, chloride and sulphate by gravimetric method.

\section{AFR Preparation}

Based on the experiments, fabric waste was micronized and blended with expired and discarded drugs. Whereas, no further processing was required for spent solvents. Thus, it is recommended that both pharma and fabric industry can undergo an MOU and an equal profit share model can be followed to enforce a win-win model.

\section{RESULTS AND DISCUSSION}

Explore and suggest the ultimate disposal pathway for barely addressed waste generated from SIPCOT industries was the ultimate objective of the study. Detailed study was carried out in terms of characterization and quality evaluation. A diverse range of waste was encountered and shortlisted through an extensive literature review. Further analytical reports are delineated below.

\section{Waste Screening}

SIPCOT comprises more than 2400 industries. Therefore an extensive literature survey was conducted to minimize the labour of ground-truthing. A review report published by honourable Supreme Court portrays profound details of all the industries operating in SIPCOT, considered as a benchmark for the present study. Corrosive chemicals such as concentrated acids and bases were opted out due to insignificance. The wastes of higher heating value and potential cementitious ingredients were only considered. A total of 27 industries were shortlisted for field perseverance and out of that only three industries identified as Pioneer Miyagi Chemicals, SPIC Pharmaceuticals Division, and Loyal Super Fabrics Limited produce wastes of higher calorific value (CV) such as spent solvents, discarded medicines, and damaged fabrics respectively.

\section{Characterization}

The crucial characteristics such as heating value, moisture content, ash content, and chloride \& sulphate content were analysed following ASTM method. The details of the observations are showcased in Table 1. The values explicitly portray the moisture content of all the specimens are significantly low and hence the process of mechanical drying eliminated. All the samples showed minimum ash contentexcept $\mathrm{I}_{3}$ with marginally higher ash value. The calorific value of $3000 \mathrm{cal} / \mathrm{gm}$ or more is generally recommended for AFR material. Therefore the values associated with $I_{1} \& \quad I_{2}$ is much greater than the acceptable limit. But the value for $I_{3}$ is slightly lower and hence needed processing. Both chloride and sulphate salts found to be within range for $I_{1} \& I_{3}$. But the 
values are quite higher than the prescribed limit of 1.5 and $2 \%$ in the case of $\mathrm{I}_{2}$.

\section{Processed AFR}

Damaged fabrics were shredded and mixed with discarded medicines in $1: 1$ ratio to compensate the excessive chloride and sulphate content, whereas spent solvent was solely well enough to be utilized as AFR.
The mixed AFR sample (M1) had a CV of $3476 \mathrm{cal} / \mathrm{gm}$ with chloride and sulphate content of $1.7 \%$ and $2.53 \%$ respectively. Thus the present study suggests to develop an alternate waste disposal pathway for the above industries by collaborating with local cement industries and facilitate revenue recovery $[7,8]$.

Table 1: Characteristics of selected waste

\begin{tabular}{|c|c|c|c|c|c|c|}
\hline $\begin{array}{c}\text { Sl. } \\
\text { No. }\end{array}$ & Industry Name & LOD (\%) & $\begin{array}{c}\text { Ash } \\
\text { Content } \\
(\%)\end{array}$ & $\begin{array}{c}\text { CV } \\
(\mathbf{c a l} / \mathbf{g m})\end{array}$ & $\begin{array}{c}\text { Chloride } \\
\text { Content (\%) }\end{array}$ & $\begin{array}{c}\text { Sulphate } \\
\text { Content (\%) }\end{array}$ \\
\hline 1 & $\begin{array}{c}\text { Pioneer Miyagi } \\
\text { Chemicals (I) }\end{array}$ & 6.5 & 3.4 & 4787 & 0.8 & 1.2 \\
\hline 2 & $\begin{array}{c}\text { SPIC Pharmaceuticals } \\
\text { Division (I) }\end{array}$ & 3.8 & 6 & 4528 & 3.2 & 4.7 \\
\hline 3 & $\begin{array}{c}\text { Loyal Super Fabrics } \\
\text { Limited (I }\end{array}$ & 5 & 12.5 & 2528 & 0.4 & 0.8 \\
\hline
\end{tabular}

\section{CONCLUSION}

The detailed study helped to understand and explore the potential of different industrial wastes from SIPCOT to be processed and utilised as AFR for the local consumers. Three potential industries were identified. Wastes were analysed, characterise, and evaluated against ASTM standard. The spent solvent generated from Pioneer Miyagi Chemicals with higher CV and low salt content found to be well suited as AFR material. Whereas, the wastes generated from SPIC Pharmaceuticals Division and Loyal Super Fabrics Limited failed to satisfy the stand-alone AFR criteria. Hence both the wastes (i.e. discarded drugs and damaged fabrics) were mixed into $1: 1$ ratio to meet the AFR criteria. Thus an understanding can beestablished between local cement industries and selected SIPCOT industries to eliminate the waste treatment cost, minimize the transport charges, and safeguard the environment.

\section{REFERENCE}

[1] Blanchard R, Albuflasa H, Musa I, Radu T, Thomson M (2020) An Evaluation of Waste Management for Energy Recovery for Bahrain. In book: Sustainable Waste Management: Policies and Case Studies, 1, pp. 247-261. DOI: 10.1007/978-981-13-7071-7_22

[2] Chatziaras N, Psomopoulos CS, Themelis NJ (2014) Use of alternative fuels in cement industry. Proceeding: 12th International Conference on Protection and 
Restoration of the Environment,At:

Skiathos island, Greece 1, pp. 521529.

[3] Zieri W, Ismail I (2018) Alternative Fuels from Waste Products in Cement Industry. In: Martínez L., Kharissova O., Kharisov B. (eds) Handbook of Ecomaterials. Springer, Cham

[4] Chandrasekhar K, Pandey S (2020) Co-processing of RDF in Cement Plants. In book: Energy Recovery Processes from Wastes Publisher: Springer. DOI: 10.1007/978-98132-9228-4_19

[5] Sadala S, Dutta S, Raghava R, Jyothsna TSS, Chakradhar B, Ghosh SK (2019) Resource recovery as alternative fuel and raw material from hazardous waste. Waste Management \& Research 114

DOI:

$10.1177 / 0734242 X 19854124$

[6] Chatziaras N, Psomopoulos CS, Themelis NJ (2016) Use of waste derived fuels in cement industry: a review. Management of Environmental Quality: An International Journal, Vol. 27 Iss 2 pp. $178-193$

[7] Baidya R, Ghosh SK (2018) Low carbon cement manufacturing in India by co-processing of alternative fuel and raw materials,
Energy Sources, Part A: Recovery, Utilization, and Environmental Effects.

DOI:

10.1080/15567036.2018.1555630

[8] Baidya R, Ghosh SK, Parlikar UV (2016) Co-processing of industrial waste in cement kiln - a robust system for material and energy recovery. Procedia Environmental Sciences 31. 309 - 317. DOI: 10.1016/j.proenv.2016.02.041. 